- X-ray microtomography is a useful 3D microscopical method in hard tissue dental research.

- X-ray microtomography images may be used for quantitative measurement.

- Results obtained using this method to measure laser (Er:YAG) ablation of dental hard tissues are compared with other studies.

\title{
Sequential 3D X-ray microtomographic measurement of enamel and dentine ablation by an Er:YAG laser
}

\author{
C. E. Mercer, ${ }^{1}$ P. Anderson ${ }^{2}$ and G. R. Davis ${ }^{3}$
}

Objective To demonstrate the progression of crater growth during repeated sequential application of an Er:YAG laser to enamel and dentine, monitored using X-ray microtomography (XMT).

Design A single centre study in which laser craters were created in blocks cut from human enamel and/or dentine under standardised and known conditions and then studied using XMT to obtain visualisation and quantification of the effects.

Setting University setting, UK, 2001.

Main outcome measures Success was judged by an ability to obtain useful 3D XMT reconstructions of the blocks during crater development, and to make measurements from these data. These measurements were compared with data obtained from similar studies using different measurement techniques.

Results Time sequences of 2D and 3D images were obtained which demonstrated the progression of laser craters in enamel and dentine. Quantitative measurements from these data enabled values to be derived for the rate of progression of crater depth per unit energy, and the volume of hard tissue removed per unit energy. These values were compared with data derived from other studies and shown to be broadly comparable. However, the present study is unique in that these values were obtained from a series of measurements of the same craters over time.

Conclusions 3D X-ray microtomography is shown to be a useful tool for quantitative measurements in dental research. For the Er:YAG laser, the relationship of laser crater depth and volume of mineral removed to applied energy was found to be linear

\section{INTRODUCTION}

In a previous paper in this journal, ${ }^{1}$ we reviewed briefly the progress of lasers in dentistry since their introduction in 1964.

1*Senior Lecturer, Department of Adult Oral Health (Conservative Dentistry), Barts and the London, Queen Mary's School of Medicine and Dentistry, ${ }^{2}$ Reader, ${ }^{3}$ Senior Lecturer, Biophysics Section, Department of Oral Growth and Development, Barts and the London, Queen Mary's School of Medicine and Dentistry

www.mds.qmw.ac.uk/dental/bip

${ }^{*}$ Correspondence to: $\operatorname{Dr}$ C. E. Mercer, Department of Adult Oral Health (Conservative Dentistry), Barts and the London, Queen Mary's School of Medicine and Dentistry, Turner Street, London E1 2AD, UK

e-mail:c.e.mercer@qmul.ac.uk

\section{Refereed paper}

Received 07.02.02; Accepted 12.09.02

๑ British Dental Journal 2003; 194: 99-104
Developments have continued. Certain lasers have now been approved by the US Food and Drugs Administration for hard tissue use and their clinical use is increasingly widely described especially in endodontics. ${ }^{2}$ The most common laser sold and employed clinically for hard tissue cutting is the Erbium YAG (Er:YAG). The wavelength $(2.94 \mu \mathrm{m})$ is well absorbed both by apatite and water, and its use is not associated with the severe hard tissue cracking and thermal damage associated with some other modalities. A recent paper in this journal described the clinical evaluation of an Erbium YAG dental laser in Scotland involving 15 dentists and 77 procedures. $^{3}$ Although other wavelengths and modalities are emerging, as understanding of the laser/tissue interaction increases, most clinical interest centres currently on the Er:YAG laser.

Laboratory X-ray microtomography (XMT) is a rapidly developing non-destructive microscopic technique for visualisation and characterisation of the internal 3-dimensional architecture of X-ray opaque materials. Single section or first generation XMT has been used in a number of dental studies, including laser ablation studies in dental enamel, ${ }^{1,4}$ mineral distribution in developing rat enamel ${ }^{5}$ and in vitro endodontic studies. ${ }^{6,7}$ A detailed review of the applications of 3D XMT in dental research have been described. ${ }^{8}$

The principles of XMT are similar to those of whole body computer aided tomography. Using modern CCD (charge coupled device) technology and a fine point source X-ray generator, it is now possible to image objects in $3 \mathrm{D}$ at a resolution of microns. The first generation XMT systems previously described used a single source and a single detector, but data collection took over 12 hours even for a single section. ${ }^{9}$ Modern CCD based 3D XMT systems can collect many slices simultaneously, significantly reducing the data collection time by orders of magnitude. Further, the substantial increase in speed of computers means that reconstructions of large 3D data sets take only a few hours to complete. In addition, developments in $3 \mathrm{D}$ visualisation and analysis software has enabled quantitative measurements to be extracted from the datasets.

The aim of the study reported in this paper was to measure the progression of crater growth during repeated sequential application of a commercial dental Er:YAG laser to human enamel and dentine. 


\section{MATERIALS AND METHODS}

\section{Tooth sample preparation}

Teeth used in this study were collected from an extraction clinic and informed consent had been given for their use in research.

Tooth rods of $2 \mathrm{~mm} \times 2 \mathrm{~mm}$ cross section containing both enamel and dentine were cut from caries free human adult premolar teeth (Fig. 1). The tooth rods were stored in de-ionised water until required. Each tooth rod was mounted onto a specifically designed relocation stage (Fig. 2a) which could be located and subsequently relocated onto the rotation axis of the XMT scanner. A $1 \mathrm{~cm}$ diameter poly(methyl methacrylate) jacket with a closed end was placed around the specimen and prior to data collection and for transport purposes this jacket was filled with de-ionised water. During data collection the tube contained a damp cloth, so that the tooth specimen remained in a humid environment throughout, preventing cracking which might result from drying.

\section{Relocation stages}

A particular aim of the experiment was to use XMT to obtain 3D images of the tooth specimens after each of a succession of laser firings. Unfortunately it was not possible to operate the laser whilst the specimen was on the XMT stage, and so the specimen had to be removed to the laser laboratory for each firing. Two kinematically designed relocation jigs were built. ${ }^{10}$ The first so that the tooth rod could be relocated exactly on the XMT scanner after each laser firing, and the second to ensure that the same area of the tooth rod surface was targeted for each laser firing. Each tooth rod and jacket assembly were attached to the upper surface of an $8.5 \mathrm{~cm}$ diameter aluminium disc (shown in Fig. 2a). On the underside, three $10 \mathrm{~mm}$ diameter steel balls were fixed to form an equilateral triangle (Fig. $2 b)$. For XMT scanning, these balls were located into three brass ' $V$ ' blocks on a mounting plate (Fig. 2c) positioned on the central rotation axis of the scanner, ensuring that the tooth rod was in the identical position for each image. Fixation was achieved using three orthodontic elastics (one shown arrowed in Fig. 2a). The accuracy of the repositioning of this apparatus has been shown to be $0.02 \mu \mathrm{m} .^{11}$ For laser firing, a similar ' $\mathrm{V}$ ' block mount was attached to an optical bench so that the aluminium disc could be accurately relocated each time. The laser hand piece was also firmly mounted, thus ensuring that the same area of tooth rod was targeted at each laser firing.

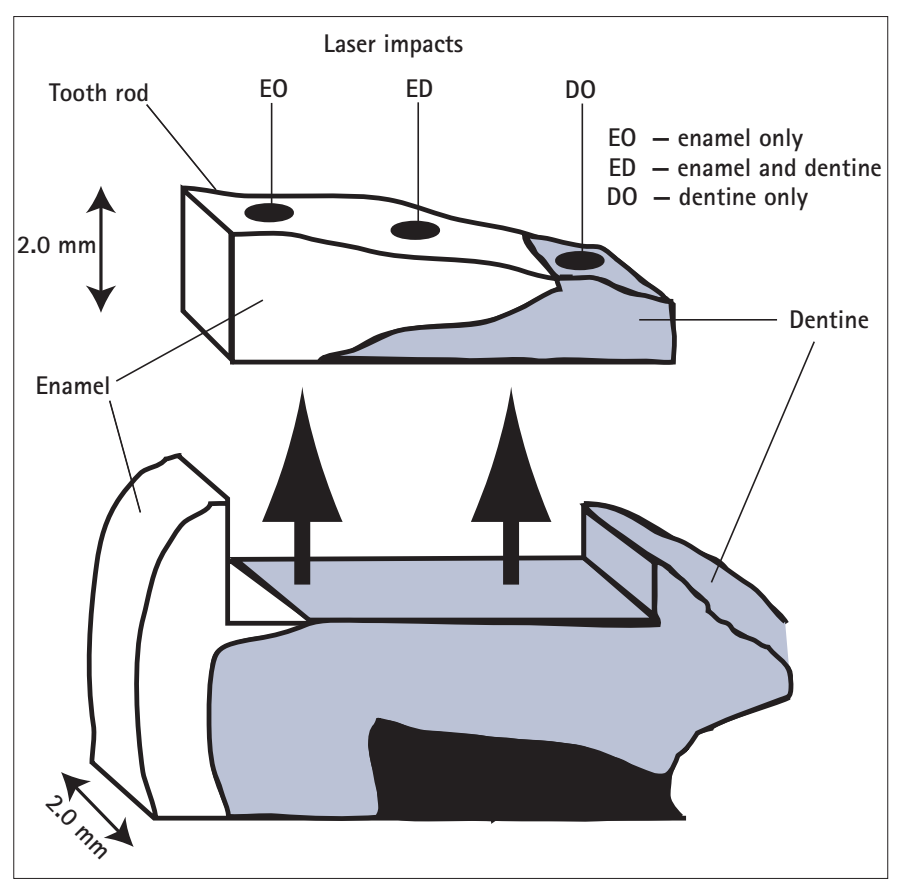

Figure 1 Schematic diagram indicating how tooth rod was cut from a $2 \mathrm{~mm}$ thick tooth section.

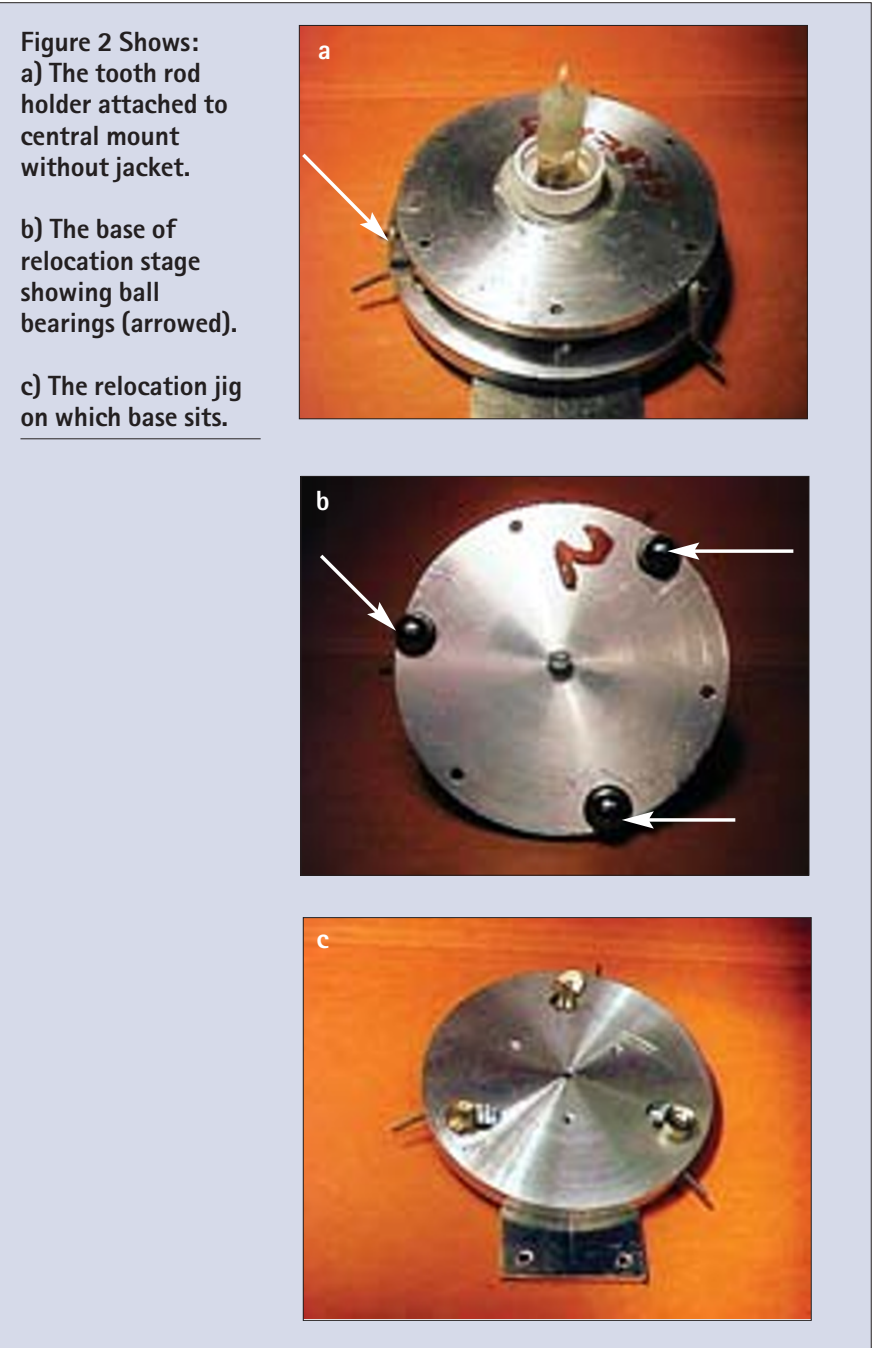

\section{The laser}

An Er:YAG dental laser (KaVo, K.E.Y.II - Fig. 3) which operates in pulsed mode was used $(\lambda=2.94 \mu \mathrm{m}$, pulse energy $400 \mathrm{~mJ}$, pulse duration 250-500 $\mu \mathrm{s}$, repetition rate 3 or $4 \mathrm{~Hz}$, focal distance $12-15 \mathrm{~mm}$, spot diameter $500 \mu \mathrm{m})$. The inbuilt water spray was turned on during all operations of the laser. Laser energy was delivered as a series of $1 \mathrm{~s}$ 'bursts' of 1,600 mJ for firings commencing on enamel (rods EO and ED), and 1,200 mJ for firings commencing on dentine (rod D0). XMT images of the tooth rods were taken following each laser firing.

\section{Protocol}

Three different tooth surfaces were studied (Fig. 1). In the first, the laser was targeted such that the crater developed in enamel only (tooth rod E0). In the second, the laser was targeted such that the crater developed in dentine only (tooth rod DO). In the third, the laser was targeted such that the crater developed initially in thin enamel, and then progressed into dentine (tooth rod ED).

\section{XMT scanner}

An XMT scanner (shown schematically in Fig. 4) typically consists of an X-ray point source, specimen turntable and image detection system. X-ray projection images are taken at a number of angles over $360^{\circ}$ as the specimen is rotated. The image detection system consists of a scintillation screen (which converts the $\mathrm{X}$-rays to visible light) coupled to a micro-channel plate image intensifier, which is further coupled to a CCD detector. The instrument used in this study was designed and built at QMUL and offers a number of advantages over other XMT scanners. ${ }^{12}$ 


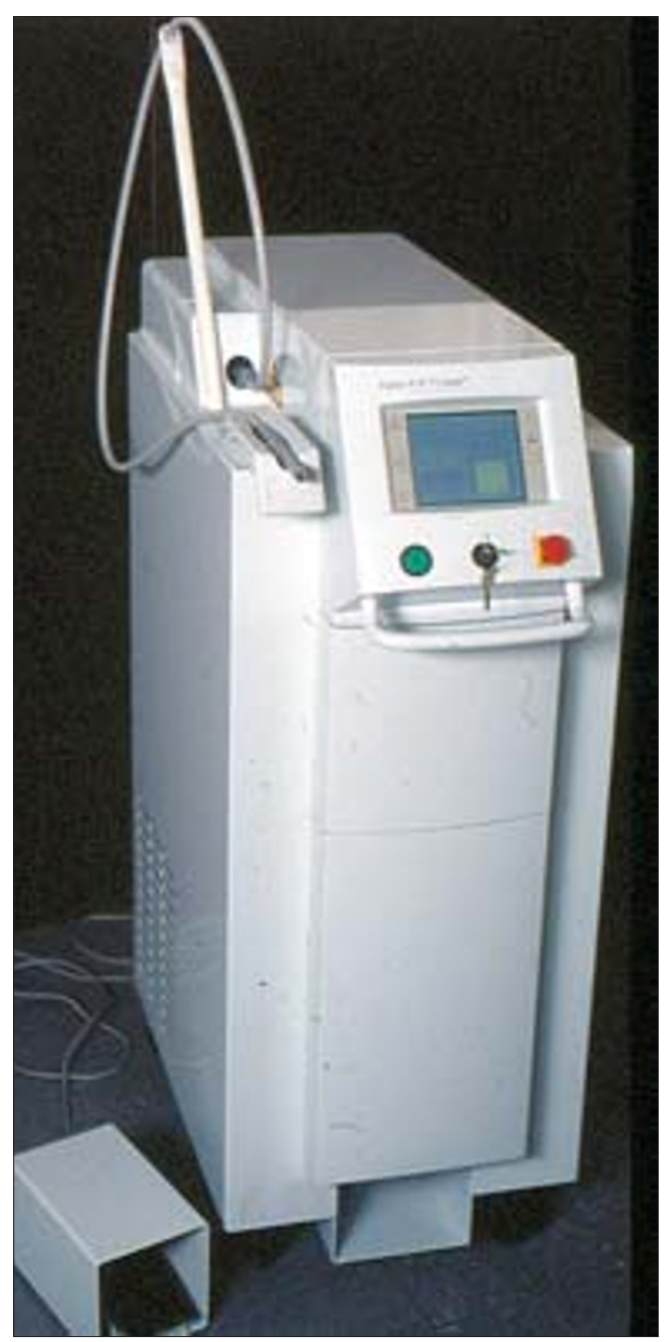

Figure $3 \mathrm{KaVo}$ KEY II Dental laser $\underline{ }$

The first is the elimination of 'ring artefacts' which arise from inhomogeneities in the response of individual elements within the array of the CCD and associated optical system. This problem is overcome by electronically 'moving' the image of the specimen across the CCD array whilst simultaneously moving the specimen in synchronism, thereby averaging the effects of varying response of individual elements in the CCD array. An important consequence of this 'time-delay integration' is the ability to image objects which are physically larger than the size of the detector and specimens up to $4 \mathrm{~cm}$ in diameter can be imaged using a $1.27 \mathrm{~cm}$ sized CCD detector. Further, the large working distance allows specimens to be located within environmental chambers so that, as in this study, the sample can be kept in a moist environment.

The X-ray source consists of an X-ray generator fitted with an $\mathrm{Ag}$ target, which was set to $50 \mathrm{kV}$ and run at $1.6 \mathrm{~mA}$ with a $2 \mathrm{~mm}$ $\mathrm{Al}$ filter. The foreshortened spot size was $100 \mu \mathrm{m} \times 100 \mu \mathrm{m}$ and the source to specimen distance was $49 \mathrm{~cm}$, with the detector positioned a further $6 \mathrm{~cm}$ away. The image detection system was calibrated using an $\mathrm{Al}$ step wedge of known dimensions.

For all the datasets collected in this study the parameters were: projections of 120 elements, 151 angular projections, 100 sections. Each data set took 10 hours to collect. Data sets were reconstructed using a standard filtered fan-beam algorithm. Further details are given in reference 12 . The dimensions of the individual picture elements in the final image (including geometric magnification) was $38.66 \mu \mathrm{m}$.

\section{Data visualisation and analysis}

The images were visualised in two formats: 2D XMT images were analysed using Optimas 6.1 (Optimas Corp, USA), 3D XMT images using IDL v3.0 (Floating Point Systems, Boulder, Co., USA, 80303) running on a DEC Alpha computer.

\section{D analysis: surface rendered images}

Surface rendered images (isosurfaces) were calculated from the complete 3D image data sets. Isosurfaces are surface contours joining all points with the same mineral concentration. A threshold value of mineral concentration for the software to generate an isosurface was selected at about half the value for that of dentine. Care must be taken in interpreting these images as the actual position of the surface contour depends on the threshold value selected. However, as in this case, where there is a sharp boundary between enamel or dentine and air at the specimen surface, this does not present a difficulty.

\section{Crater volume measurements}

The volume of each laser crater as a function of applied laser energy was calculated from the 3D image data sets. The threshold value was selected to be representative of the surface of the tooth (well below the mineral concentration of dentine in order to include dentine in the image). The volume of mineral removed was calculated by subtracting from the original number of voxels above the set threshold, the number of voxels

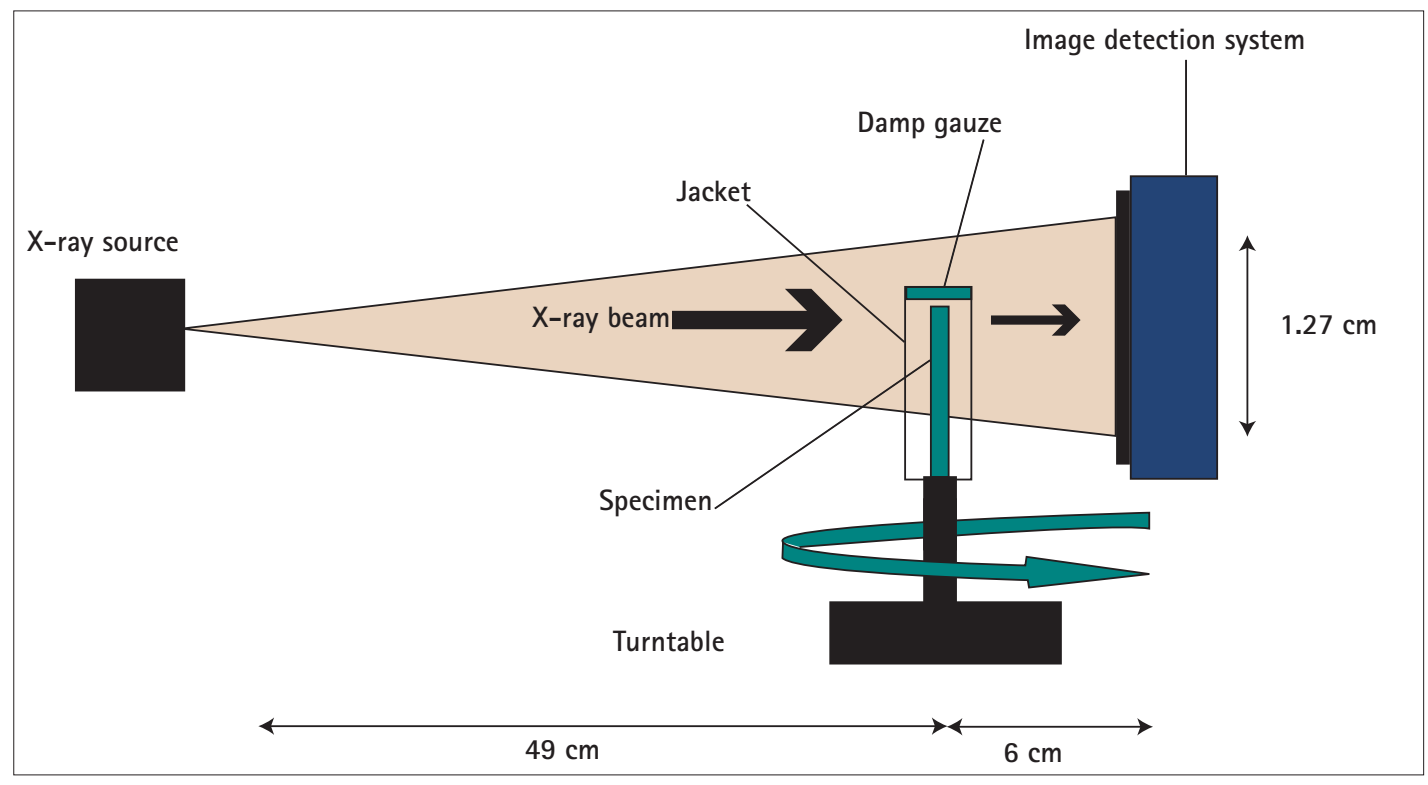


which remained after each laser firing. Using the known voxel dimensions, the volume of the laser crater at each stage during the sequence of crater development was calculated. For each experiment, laser cavity volume was plotted as a function of applied energy.

\section{D grey scale images (XMT 'sections')}

The 3D XMT image datasets each contained 100 adjacent sections (38.66 $\mu \mathrm{m}$ apart). Although the reconstructed image dataset was stored as a 3D array, each of the sections can be individually displayed as a 2D grey scale section of $120 \times 120$ pixels, sliced at any selected orientation. Each pixel (2D picture element) is stored as a number representing the average mineral concentration of the principal X-ray absorber in dental hard tissues, calcium hydroxyapatite (HAP). These XMT sections are similar in appearance to microradiographs of thinly cut sections. Linear measurements, for example the depth of a laser crater, were calculated from the images using the pixel dimensions.

\section{Crater depth measurements}

In this study, the crater depth in each experiment was defined as follows. Using the final image in each sequence, the XMT section in which the greatest crater depth was observed was selected. Using this slice, a datum point was positioned approximately midway on a line drawn across the mouth of the crater, and the $\mathrm{x}, \mathrm{y}$ and $\mathrm{z}$ co-ordinates of the datum point noted. The section with the identical slice number was extracted from each 3D
XMT data sets taken during the development of the same crater. The crater depth in each of these 2D images was defined as the distance from the datum point to the bottom of the laser crater. Because the relocation stage accurately repositioned the stage, the same datum point could be used for any image in a sequence thus ensuring that the depth was measured from the same position on each image.

The laser crater depth was measured for each of the 3D data sets collected. The energy delivered to each laser impact site was calculated from the accumulated number of pulses which had been applied after any given time. For each experiment, laser crater depth was plotted as a function of applied energy.

\section{RESULTS}

In Figure 5 columns A, B, and C show typical examples of series of $2 \mathrm{D}$ grey scale sections (section selected is at the position of maximum depth), indicating the development of laser craters in rods of type E0, DO and ED respectively. Each section was taken after each firing (specimen 1 prior to lasing was lost) - at intervals of 1,600 mJ for EO and ED rods, and intervals of 1,200 mJ for D0 rods.

In Figure 6 columns A, B and C shows the corresponding surface rendered images of the same laser craters shown in Figure 5.

Figure 7a shows plots of crater depth as a function of total energy delivered, for each laser crater. Similarly, Figure $7 \mathrm{~b}$ shows plots of volume of tissue removed as a function of energy delivered for each crater. Linear least squares analysis was carried out on both these plots.
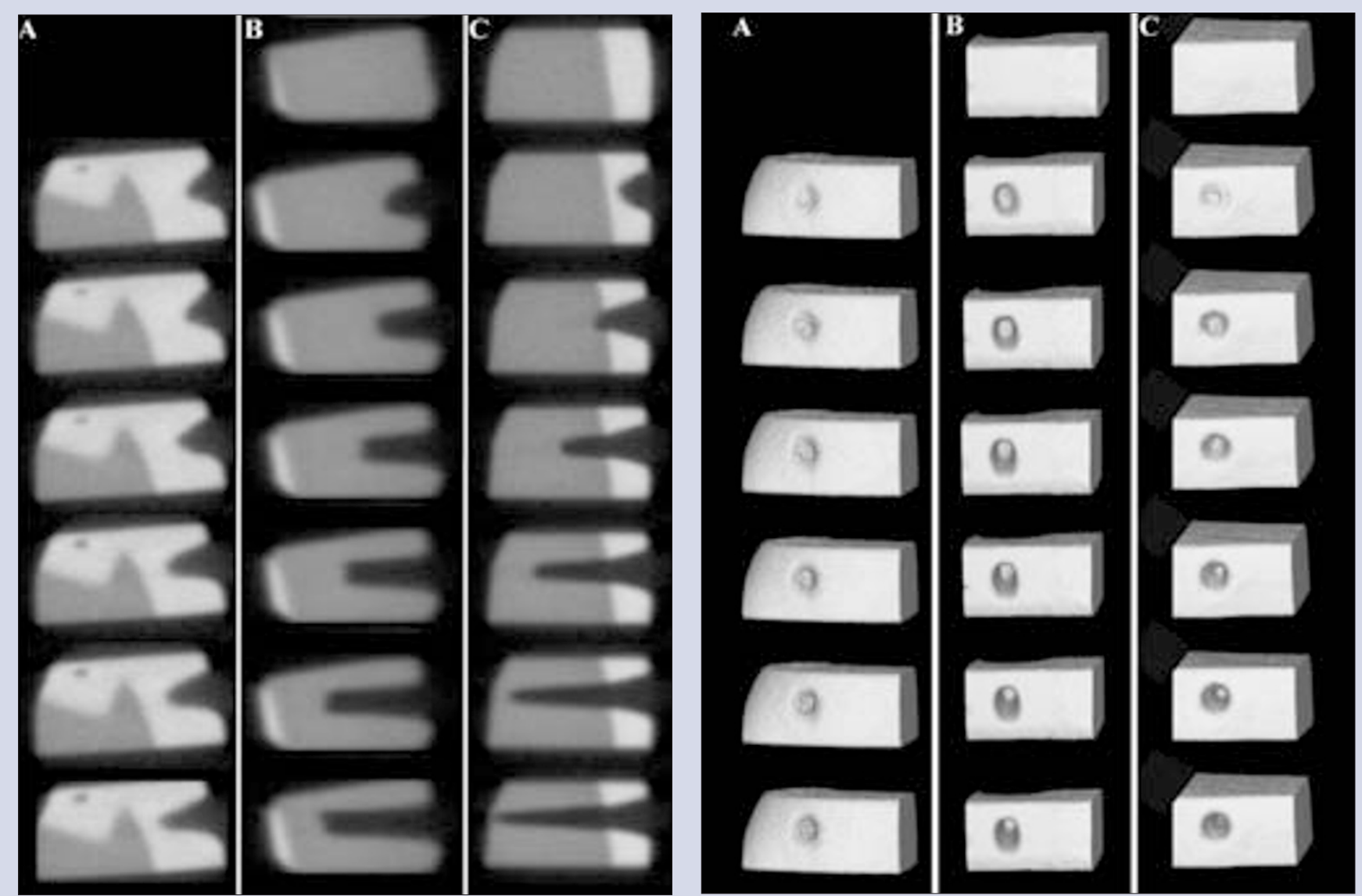

Figure 5 Sequence of 2D XMT images at the same position in:

A) tooth rod EO

B) tooth rod DO

C) tooth rod ED

following a sequence of laser bursts as laser crater develops.

Figure 6 Sequence of 3D XMT images of part of tooth rods containing a laser crater shown in Figure 5. 


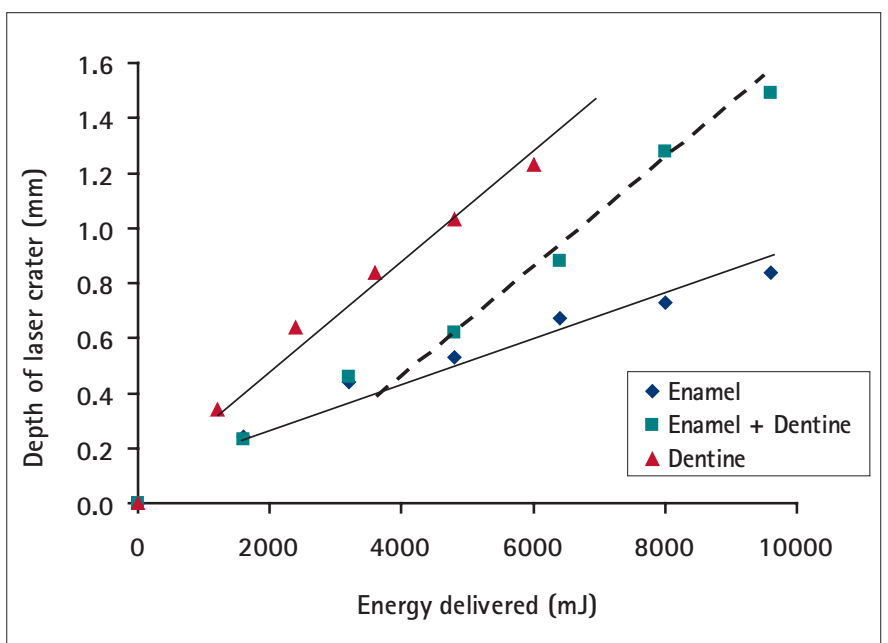

Figure 7a Plot of crater depth as a function of applied laser energy. Solid lines are fitted to experimental data. Dashed line is drawn parallel to line dentine fitted to dentine data showing that for tooth rod ED as crater moves in dentine, gradient changes from a value similar to that in enamel to a value similar to that in dentine.

\section{DISCUSSION}

This study has specifically demonstrated the application of 3D XMT for real-time studies of the progression of laser crater development in dental hard tissues. As XMT becomes increasingly accessible to dental research, many previously impractical quantitative studies measuring changes in the internal structure of dental hard tissues become possible.

The ability to use an accurate relocation jig for sequential measurements has been demonstrated, and this technique will be of interest to other dental research workers requiring repeated relocation of specimens following removal from the apparatus for treatment.

Both the 2D and the 3D XMT images have highlighted a number of features associated with the development of laser craters. In all previous studies investigating laser ablation, measurements were only made at the end point of crater formation and consequently no data was available about crater development. In this study, the rate of laser crater development as a function of applied energy was calculated from regression lines fitted to a time series of measurements on the same specimen.

The plots in Figures $7 \mathrm{a}$ and $7 \mathrm{~b}$ show an approximately linear progression of laser crater depth and volume for the enamel (EO) and the dentine (D0) samples. Linear least squares fitting was applied to the data after the first point for each condition, but were not extrapolated back to the abscissa, since the relationship between laser energy and ablation in that area is clearly not linear, involving complex mechanisms before ablation thresholds are exceeded. Further studies are intended to investigate this area in more detail.

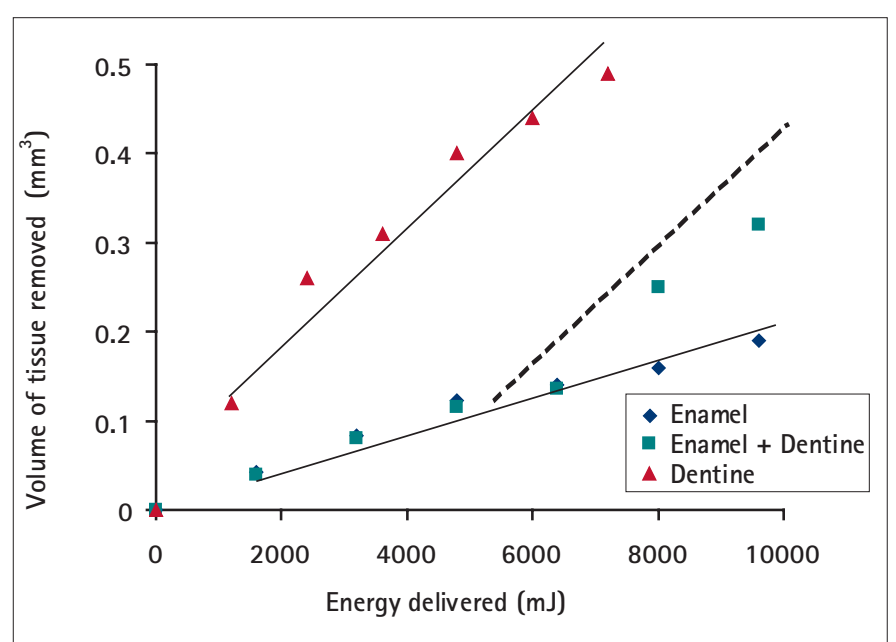

Figure 7b Plot of volume of mineral removed as a function of applied laser energy. Solid lines are fitted to experimental data. Dashed line is drawn parallel to line dentine fitted to dentine data showing that for tooth rod ED as crater moves in dentine, gradient changes from a value similar to that in enamel to a value similar to that in dentine.

For the sample in which the crater progressed from enamel into dentine (ED), the rate of progression of both lesion depth and volume removed suddenly increased from a value similar to that in enamel only, to a value similar to that in dentine only. This sudden increase occurred when the laser impact site progressed from enamel into dentine.

Similarly, both the 2D and the 3D XMT images showed that the diameter of the laser impact sites did not enlarge significantly with successive impacts, which confirms the findings by Mercer who used vertical scanning interferometry (VSI) ${ }^{13}$ to measure craters in enamel produced using increasing amounts of laser energy. ${ }^{14}$ This observation can be partly explained by the observation of Hibst and Keller, ${ }^{15}$ who plotted a spatial profile showing that the energy across the useful width of the Er:YAG beam was fairly constant but also by the known strong absorption of the Er:YAG wavelength by apatite.

The XMT sections shown in Figure 5 clearly show that the diameter of the crater as a function of depth diminished in all cases, confirming the findings of Wannop et al. ${ }^{16}$

Few studies have produced quantitative data about the hard tissue cutting abilities of lasers, and this is further complicated as authors have used a variety of methods of measurement, and expressed their results in terms of different units. For purposes of comparison, we have tabulated available data from many other studies (Table 1) but in order to make direct comparisons from these studies employing different measurement techniques, we have had to convert the data as given, to common linear $\left(\mu \mathrm{m} / \mathrm{J}^{-1}\right)$ and volumetric units $\left(\mathrm{mm}^{3} / \mathrm{J}^{-1}\right)$. We do not know if water spray was employed in all the other studies.

Table 1 A comparison of previously reported values for Er:YAG laser ablation of enamel (E) and dentine (D) with those obtained in the current study.

\begin{tabular}{|c|c|c|c|c|}
\hline Author & Technique stated & Tissue & Linear $\left(\mu \mathrm{m} \mathrm{J}^{-1}\right)$ & Volumetric $\left(\mathrm{mm}^{3} \mathrm{~J}^{-1}\right)$ \\
\hline Ertl and Muller (1992) ${ }^{17}$ & Stereomicroscopy & $E$ & - & $3.8 \mathrm{E}-2$ \\
\hline Li et al. $(1992)^{18}$ & Optical & $\mathrm{E}$ & $255-220$ & \\
\hline Rizoiu and DeShazer (1995) ${ }^{19}$ & No details given & $\mathrm{E}$ & - & $2.1 \mathrm{E}-2$ \\
\hline Mercer $(1998)^{14}$ & VSI & $\mathrm{E}$ & 110 & $3.0 \mathrm{E}-2$ \\
\hline Present study & XMT & $\mathrm{E}$ & 97 & $2.1 \mathrm{E}-2$ \\
\hline Ertl and Muller (1992) ${ }^{17}$ & Stereomicroscopy & $\mathrm{D}$ & - & $8.0 \mathrm{E}-2$ \\
\hline Li etal. $(1992)^{18}$ & Optical & $\mathrm{D}$ & $496-252$ & \\
\hline Attrill et al. $(1995)^{20}$ & Profilometry & $\mathrm{D}$ & - & $20.0 \mathrm{E}-2$ \\
\hline Chao et al. $(1996)^{21}$ & No details & D & $154 / 175$ & \\
\hline Mehl et al. (1997) 22 & Laser 3D scanner & D & - & $6.8 \mathrm{E}-2$ \\
\hline Mercer $(1998)^{14}$ & VSI & D & 250 & $8.0 \mathrm{E}-2$ \\
\hline Present study & XMT & D & 220 & $6.9 \mathrm{E}-2$ \\
\hline Vickers et al. $(1992)^{23}$ & Dissecting microscope & e E and D & 144 (saline) 99 (formalin) & - \\
\hline
\end{tabular}


Table 1 shows the similarity of the data obtained in this study compared with nearly all of the previous studies, although our values are generally slightly lower. However, it must be pointed out that in all other studies the data were obtained from a single measurement. In our case, the rate of mineral loss per unit energy delivered is obtained from linear least squares fitting series of at least eight measurements in each case.

\section{CONCLUSIONS}

3D X-ray microtomography is shown to be a useful tool for quantitative measurements in dental research. For the Er:YAG laser, the relationship of laser cavity depth and volume of mineral removed to applied energy was found to be linear.

1. Mercer CE, Anderson P.X-ray microtomography: a novel technique for the quantification of effects in enamel following CO2 laser application. BrDent J 1996; 180: 451-455.

2. Cozean C, Arcoria C J, Pellagalli J, Powell G L. Dentistry for the 21 st century? Erbium:YAG laser for teeth. JAm Dent Assoc 1997; 128: 1080-1087.

3. Evans D J, Matthews S, Pitts N B, Longbottom C. Nugent Z J. A clinical evaluation of an Erbium:YAG laser for dental cavity preparation. Br Dent J 2000; 188: 677-679.

4. Groth E D B, Mercer CE, Anderson P. Microtomographic analysis of subsurface enamel and dentine following Er:YAG laser and acid etching. EurJ Prosthodont Rest Dent 2001: 9: 73-79.

5. Wong FS L, Elliott J C, Davis G R, Anderson P. X-ray microtomographic study of the mineral distribution in rat incisor enamel. J Anat 2000; 196: 405-413.

6. Dowker SE P, Davis G R, Elliott J C. Wong FS L. X-ray microtomography: 3-dimensional imaging of teeth for computer assisted learning. Eur J DentEduc; 1997 1:61-63.

7. Dowker SE P, Davis G R, Elliott J C, Wong FS L. X-ray microtomography. Nondestructive three-dimensional imaging for in vitro endodontic studies. Oral Surg Oral Med Oral Pathol Oral Radiol Endod 1997; 83: 510-516.

8. Elliott J C, Davis, G R, Anderson P, Wong FS L, Dowker S E P, Mercer C E. Application of laboratory microtomography to the study of mineralised tissues. Anales de Quimica IntEd 1997; 93: S77-S82.
9. Elliott J C, Anderson P, Davis G R, Wong FS L, Dover S D. Computed tomography Part II: The practical use of a single source and detector. JOM-J Min Met Mat Soc 1994; 46: 11-19.

10. Elliott A, Home Dickson J. Laboratory instruments, their design and applications. p88. London: Chapman and Hall,1959.

11. Zhang XZ, Anderson P, Dowker S E P, Elliott J C. Optical profilometric study of changes in surface roughness of enamel during in vitro demineralization. Caries Res 2000; 34: 164-174.

12. Davis G R Elliott J C. X-ray microtomography scanner using time-delay integration for elimination of ring artifacts in the reconstructed image. Nucl Instr Meth Phys Res A 1997; 394: 157-162.

13. Wyant J C. Computerized interferometric measurement of surface microstructure. Proc SPIE 1995; 2576: 122-130

14. Mercer C E. The quantitative investigation of some effects of a range of lasers on dental hard tissues. PhD Thesis University of London, 1998.

15. Hibst $R$, Keller $U$. Experimental studies of the application of the Er:YAG laser on dental hard substances: 1. Measurement of the ablation rate. Lasers Surg Med. 1989; 9: 338344

16. Wannop N M, Dickinson M R, King TA. Erbium:YAG laser radiation interaction with dental tissue. SPIE (Dental Applications of Lasers) 1993: 2080: 33-43.

17. Ertl Th, Muller G. Ablation efficiency of pulsed lasers during preparation of dental hard tissue. pp 233-234. In Proceedings of the ISLD Third International Congress on Lasers in Dentistry. pp 233-234. Salt Lake City, 1992.

18. Li Z-Z, Code J E, van de Merwe W P. Er:YAG Laser ablation of enamel and dentin of human teeth: determination of ablation rates at various fluences and pulse repetition rates. Lasers Surg Med 1992; 12: 625-630.

19. Attrill D C, Blinkhorn AS, Davies R M, Dickinson M R, King TA. Erbium:YAG and Holmium:YAG laser ablation of dentine. J Dent Res 1995; 74: 868 Abstract No 369.

20. Rizoiu I M, DeShazer L G. Water spray assisted erbium laser cutting of dental hard tissues. ASLMS Abstracts 1995: Supp: 16 Abstract No 67.

21. Chao W S, Shen B I, White J M. Ablation rate of dentin and enamel utilizing contact Er:YAG laser. J Dent Res 1996; 75: 587.

22. Mehl A, Kremers L, Salzmann K, Hickel R. 3D volume-ablation rate and thermal side effects with the Er:YAG and Nd.YAG laser. Dent Mater 1997: 13: 246-251.

23. Vickers $V A$, Jacques $S L$, Powers J M, Martin J W. Ablation of hard dental tissues with the Er:YAG Laser. In Proceedings of the ISLD Third International Congress on Lasers in Dentistry. pp 257-258. Salt Lake City, 1992. 